Discussion Paper No. 17-025

Strategic Delegation and International Permit Markets: Why Linking May Fail

Wolfgang Habla and Ralph Winkler

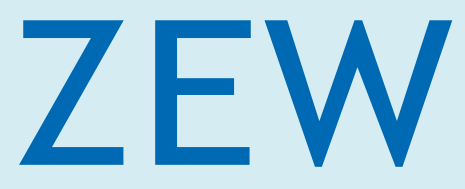

Zentrum für Europäische Wirtschaftsforschung $\mathrm{GmbH}$ Centre for European Economic Research 
Discussion Paper No. 17-025

\title{
Strategic Delegation and International Permit Markets: Why Linking May Fail
}

\author{
Wolfgang Habla and Ralph Winkler
}

Download this ZEW Discussion Paper from our ftp server:

http://ftp.zew.de/pub/zew-docs/dp/dp17025.pdf

Die Discussion Papers dienen einer möglichst schnellen Verbreitung von neueren Forschungsarbeiten des ZEW. Die Beiträge liegen in alleiniger Verantwortung der Autoren und stellen nicht notwendigerweise die Meinung des ZEW dar.

Discussion Papers are intended to make results of ZEW research promptly available to other economists in order to encourage discussion and suggestions for revisions. The authors are solely responsible for the contents which do not necessarily represent the opinion of the ZEW. 


\title{
Strategic Delegation and International Permit Markets: Why Linking May Fail*
}

\author{
Wolfgang Habla ${ }^{\dagger}$ and Ralph Winkler ${ }^{\ddagger}$ \\ $\dagger$ Department of Environmental and Resource Economics, Environmental Management, \\ Centre for European Economic Research (ZEW) \\ L7, 1, DE-68161 Mannheim, Germany; habla@zew.de \\ $\ddagger$ Department of Economics and \\ Oeschger Centre for Climate Change Research, University of Bern \\ Schanzeneckstrasse 1, CH-3012 Bern, Switzerland; mail@ralph-winkler.de
}

This version: May 2017

\begin{abstract}
We analyse a principal-agent relationship in the context of international climate policy. Principals in two countries first decide whether to merge domestic emission permit markets to an international market, then delegate the domestic permit supply to an agent. We find that principals select agents caring less for environmental damages than they do themselves in case of an international market regime, while they opt for self-representation in case of domestic markets. This strategic delegation incentive renders the linking of permit markets less attractive and constitutes a novel explanation for the reluctance to establish non-cooperative international permit markets.
\end{abstract}

Keywords: non-cooperative climate policy, political economy, emissions trading, linking of permit markets, strategic delegation, strategic voting

JEL-Classification: D72, H23, H41, Q54, Q58

\footnotetext{
* This paper was previously circulated under the title "Strategic Delegation and Non-cooperative International Permit Markets". We are grateful to an anonymous reviewer whose comments on Habla and Winkler (2013) triggered the idea for this paper. We also thank Stefan Ambec, Cécile Aubert, Antoine Dechezleprêtre, Simon Dietz, Timo Goeschl, Corina Haita, Andreas Lange, Antony Millner, Amrish Patel, Grisha Perino, Kerstin Roeder, François Salanié, Thomas Sterner, Luca Taschini, Alessandro Tavoni, Nicolas Treich, participants in the EAERE conference in Toulouse (2013) and the workshop "Énergie et territoires" in Dijon (2015), as well as seminar participants at the Universities of Bern, Gothenburg, Graz, Hamburg, Heidelberg, the London School of Economics, Toulouse School of Economics, ETH Zurich, Ifo Institute Munich and the Graduate Institute, Geneva, for valuable comments on an earlier draft. Habla acknowledges the generous financial support from the FORMAS research program COMMONS.
} 


\section{Introduction}

Efforts to mitigate anthropogenic climate change are plagued by the public good property of greenhouse gas emissions reductions. Each country's efforts to control emissions will benefit all countries in a non-exclusive and non-rival manner. The absence of a supranational authority to enforce efficient provision leads to the observed under-provision of emissions reductions. As a potential remedy, international emission permit markets have been proposed (Flachsland et al. 2009; Jaffe et al. 2009; Green et al. 2014).

On the one hand, international permit markets promise efficiency gains, as marginal abatement costs are equalized across firms and countries, which is a necessary condition for efficiency (Montgomery 1972). On the other hand, the total number of permits in such a trading scheme is not necessarily efficient, because each country is free to decide on the number of permits it wants to issue within its own jurisdiction. In fact, some countries might be tempted to issue more permits than they would do in the absence of international trade in permits, because they might gain from selling permits to other countries. Helm (2003), among others, shows that the non-cooperative choice of allowances under an international permit market (which we will refer to as a "non-cooperative" international permit market) might increase total emissions by so much that an international permit market becomes unattractive for one or more countries. ${ }^{1}$ Yet, Carbone et al. (2009) demonstrate that international permit markets exhibit substantial potential for greenhouse gas reductions under certain circumstances. In particular, linking the permit markets of countries with high carbon efficiency (i.e., high marginal benefits of greenhouse gas emissions) and high willingness to pay for emissions reductions (i.e., high marginal damages) and countries with low carbon efficiency and low willingness to pay leads to a Pareto improvement, in which efficiency gains due to equalizing marginal abatement costs are realized and total emissions decline. Despite these favourable characteristics, we have yet to observe the formation of many such markets. Only Liechtenstein, Iceland and Norway joined the European Union's Emissions Trading Scheme (EU-ETS), and California and Québec linked their cap-and-trade systems in $2014 .^{2}$

In this paper, we offer a novel explanation for the observed reluctance in linking emission permit markets. We show that, even in these instances where an international permit market is beneficial to countries in the aforementioned model frameworks, this may not be the

\footnotetext{
${ }^{1}$ Copeland and Taylor (2005) also find that, when taking international trade in goods into account, permit trading between two countries may harm at least one country by causing a deterioration in the terms of trade and/or raising the emission levels in unconstrained (with respect to emissions) countries.

${ }^{2}$ Australia, which had already announced a plan to establish a domestic permit market and link it with the EU's scheme, abandoned these plans after a change in government. Moreover, the EU-ETS does not strictly fit our definition of non-cooperative international permit market, because of the supranational authority that the EU exerts on the national governments with respect to domestic emission permit levels.
} 
case anymore when we take the hierarchical structure of climate policy into account. By "hierarchical" we mean that political decisions in modern societies are not made by a single - let alone benevolent - decision maker. For example, representative democracies typically feature a chain of delegation from voters to those who govern (Strøm 2000): (i) from voters to elected representatives, (ii) from legislators to the executive branch (head of government), (iii) from the head of government to the heads of different executive departments, and (iv) from these heads to civil servants. ${ }^{3}$ In all these situations, one party (an agent) acts on behalf of another (the principal) because the principal either lacks the information or skills of the agent, or simply the time. Another reason for delegation is that the choice of an agent with certain preferences enables the principal to credibly commit to a particular policy (e.g., Perino 2010). We focus on the latter purpose of delegation.

In the realm of climate policy, the most common form of delegation is that a country's government - the principal - decides upon the rough orientation of the policy (e.g., on whether a permit market or a tax will be implemented) and delegates the implementation of this policy to the minister of environment - the agent. The appointment of a minister with a particular political agenda that is publicly observable and well-known can be regarded as an (additional) instrument to credibly commit a country in the international policy arena. ${ }^{4}$

We model the principal-agent relationship outlined above in a two-country framework. In a first step, the principals of both countries determine whether to link their domestic emission permit markets to an international market that is formed if and only if both principals agree to do so. Second, each principal selects one agent who is empowered to issue emission permits. Then, the selected agents in both countries non-cooperatively determine the number of emission permits issued to domestic firms. Finally, trading of permits - within or between countries, contingent on the regime chosen in the first stage - takes place.

Assuming constant marginal damages, we find that the principals of both countries appoint agents with the same preferences as they have themselves under domestic permit markets but agents who care less about environmental damages than they do under an international permit market regime. The intuition for this result is that permit choices by the agents

\footnotetext{
${ }^{3}$ While for autocratic regimes the first link of this chain is obviously missing, we still observe delegation patterns as in (ii), (iii) and (iv).

${ }^{4}$ The EU's climate policy, for example, is represented by the Commissioner for Climate Action whose mission is to "formulate and implement climate policies and strategies" at the EU and the international level. This post was created in 2010, splitting it from the environmental portfolio of the Directorate-General for Environment, and thus it figures prominently in the EU's policy portfolio. The appointment of Miguel Arias Cañete as the Commissioner for Climate Action in November 2014 can be seen as a strong "signal" to the international community, since Cañete is a politician of the centre-right and, in addition, his family was involved in the oil industry. After accusations of possible conflicts of interest, he and his son resigned from the boards of oil companies Petrolifera Ducar and Petrologis Canarias in September 2014 (Financial Times 2014).
} 
are dominant strategies under the former regime but strategic substitutes under the latter regime due to the international trade of permits. On an international market, it is beneficial for each country to issue more permits and pass on part of the abatement effort to the other country, because the marginal benefits from additional emissions, which are equal to the equilibrium permit price, decrease by less than under domestic permit markets. The principals in both countries can achieve higher issuance of permits by choosing agents with a lower valuation of environmental damages than they exhibit themselves. While the previous literature arrived at similar results in the absence of an international permit market (e.g., Segendorff 1998; Siqueira 2003 and Buchholz et al. 2005), these results crucially depended on the assumption of increasing marginal damages of emissions.

Because global emissions unambiguously rise under the international permit market regime compared to the case when principals do not have the possibility to delegate, an international permit market becomes less attractive to at least one principal. Thus, strategic delegation renders the formation of an international market less likely. Overall, we find that the conditions for the formation of an international permit market are less favourable than suggested by the standard permit market literature, which neglects the hierarchical structure of international climate policy.

Our paper contributes to several strands of literature. It builds on and extends the literature on non-cooperative international permit markets, developed in Helm (2003), Carbone et al. (2009), Holtsmark and Sommervoll (2012) and Helm and Pichler (2015). While these papers assume that countries are represented by one welfare-maximizing decision maker (the government), we explicitly account for the principal-agent relationship between different bodies involved in international policy making within a single country, for example, an incumbent government or president that serves as the principal and a selected executive or government agency that serves as an agent. In this regard, we heavily draw on the strategic delegation literature.

The first papers on strategic delegation can be found in the Industrial Organization (IO) literature analyzing the delegation of managerial decisions from shareholders to chief executive officers. Vickers (1985), Fershtman and Judd (1987) and Sklivas (1987) consider a managerial compensation scheme that is based not only on profits but also on sales respectively revenues. They show that in a duopoly or oligopoly with quantity-setting firms, the profits of the owner who designs such a contract exceed those of her rivals who just prescribe their managers to maximize profits, because the additional incentive device is common knowledge (or can be inferred in repeated games) and thus serves as a credible commitment to a particular strategy. This reasoning does not only apply to markets in which the performance of each firm depends on the choices of all firms (for an excellent survey see Kopel and Pezzino 
forthcoming). It is relevant for all environments of strategic interdependence in which one player's payoff depends on the decisions of other players. It comes as no surprise that the concept of strategic delegation subsequently found its way into the literature on negotiation and cooperation (Crawford and Varian 1979; Sobel 1981; Jones 1989; Burtraw 1992, 1993; Segendorff 1998) where it has been utilized in various contexts with inter-agent spillovers, such as environmental policy or the provision of public goods more generally. In contrast to the early IO papers, the principal in these papers does not misrepresent her own preferences by incentivizing the agent with an additional instrument. Instead, she is able to raise her payoff by delegating the task at hand to an agent with preferences different from her own. It is also worth mentioning that strategic delegation is labeled as "strategic voting" whenever the principal is the electorate or, more precisely, the median voter and the elected government is the agent (Persson and Tabellini 1992).

Siqueira (2003), Buchholz et al. (2005), Roelfsema (2007) and Hattori (2010) analyse strategic voting in the context of environmental policy. While the first three contributions exclusively focus on environmental taxation, Hattori (2010) also examines the outcome of strategic voting under emissions caps. Siqueira (2003) and Buchholz et al. (2005) both find that voters' selection of agents is biased toward politicians who are less green than the median voter. By electing a more "conservative" politician, the home country commits itself to a lower tax on pollution, shifting the burden of a cleaner environment to the foreign country. By contrast, Roelfsema (2007) accounts for emissions leakage through shifts in production and finds that median voters may delegate to politicians who place greater weight on environmental damage than they do themselves, whenever their preferences for the environment relative to their valuation of firms' profits are sufficiently strong. However, this result breaks down in the case of perfect pollution spillovers, such as the emission and diffusion of greenhouse gases as in our paper. Hattori (2010) allows for different degrees of product differentiation and alternative modes of competition, i.e., competition on quantities but also on prices. His general finding is that, when the policy choices are strategic substitutes (complements), a less (more) green policy maker is elected in the non-cooperative equilibrium. As in Siqueira (2003) and Roelfsema (2007), the agents selected by the principals in our model do not engage in bargaining but rather set environmental policies non-cooperatively. In contrast to the aforementioned papers, we examine delegation not only under caps but also under an international permit market. We find that an international permit market induces strategic substitutability of policy choices and thus changes the incentives to delegate strategically. In fact, as we abstract from convex damages, the international permit market is the only source of strategic delegation incentives in our model.

Strategic delegation in the provision of public goods with cross-border externalities more generally has been examined by Kempf and Rossignol (2013) and Loeper (2017). The authors 
of the former paper show that any international agreement that is negotiated by national delegates involves higher public good provisions than in the case of non-cooperative policies, taking feasibility, efficiency and equity constraints into account. In their model, the choice of delegates is highly dependent on the distributive characteristics of the proposed agreement. Loeper (2017) proves that whether cooperation between national delegates is beneficial only depends on the type of public good considered and, more specifically, on the curvature of the demand for the public good but not on voters' preferences, the magnitude of the crossborder externalities, nor the size, bargaining power or efficiency of each country in providing the public good. Another strand of this literature deals with the provision of public goods in federations that are characterized by fiscal arrangements or different majoritarian rules; see, e.g., Besley and Coate (2003), Redoano and Scharf (2004), Dur and Roelfsema (2005), Harstad (2010) and Christiansen (2013).

The broader literature on linking offers several explanations for why "bottom-up" (or noncooperative in our terminology) approaches to permit trading have not been successful. Among the obstacles that have been identified are different levels of ambition, competing domestic policy objectives, objections to financial transfers and the difficulty of regulatory coordination (Green et al. 2014). We contribute to this literature by suggesting that the hierarchical structures underlying environmental policy may well be a reason for the rejection of otherwise beneficial policies. With respect to hierarchical policy structures within countries, our paper is related to Habla and Winkler (2013) and Marchiori et al. (2017), in which the influence of legislative lobbying on the formation of international permit markets and on international environmental agreements, respectively, is analysed.

\section{The model}

We consider two countries, indexed by $i=1,2$ and $-i=\{1,2\} \backslash i .^{5}$ In each country $i$, emissions $e_{i}$ imply country-specific benefits from the productive activities of a representative firm, characterized by a concave quadratic benefit function $B\left(e_{i}\right)$, while global emissions $E=e_{1}+e_{2}$ cause linearly increasing country-specific damages, $D_{i}(E):^{6}$

$$
\begin{aligned}
& B_{i}\left(e_{i}\right)=\frac{1}{\phi_{i}} e_{i}\left(\epsilon_{i}-\frac{1}{2} e_{i}\right), \quad B_{i}^{\prime}\left(e_{i}\right)=\frac{\epsilon_{i}-e_{i}}{\phi_{i}}, \quad B_{i}^{\prime \prime}=-\frac{1}{\phi_{i}}, \\
& D_{i}(E)=\delta_{i} E, \quad D_{i}^{\prime}=\delta_{i}, \quad D_{i}^{\prime \prime}=0,
\end{aligned}
$$

\footnotetext{
${ }^{5}$ All our results can be generalized to $n$ countries in a straightforward manner.

${ }^{6}$ We employ the assumption of constant marginal damages for two reasons. First, together with the assumption of a quadratic benefit function it allows to derive closed-form analytical solutions. Second, it poses the least favourable conditions for strategic delegation to occur. Yet, we show that strategic delegation still occurs in the case of an international permit market. We further discuss the assumption of a linear damage function in Section 7.
} 
where $\epsilon_{i} \geq e_{i}$ denotes business-as-usual emissions in the absence of any climate policy, $\phi_{i}>0$ is a parameter that is inversely related to the carbon efficiency and $\delta_{i} \geq 0$ denotes the constant marginal environmental damages in country $i$. In addition, we define the following abbreviations:

$$
\epsilon \equiv \epsilon_{1}+\epsilon_{2}, \quad \phi \equiv \phi_{1}+\phi_{2}
$$

\subsection{Non-cooperative international climate policy}

Both countries establish perfectly competitive domestic emission permit markets and determine, non-cooperatively, the number of permits $\omega_{i}$ issued to a representative domestic firm. As firms in all countries $i$ require emission permits for an amount equal to the emissions $e_{i}$ they produce, global emissions are given by the sum of emission permits issued, $E=\omega_{1}+\omega_{2}$. Countries may agree to link their domestic markets and form an international market. Then permits issued by both countries are non-discriminatorily traded on a perfectly competitive international market.

Restricting emissions imposes a compliance cost on the representative firms and thus reduces profits. If permits are traded internationally, firms have an opportunity to either generate additional profits by selling permits or reduce the compliance cost by buying permits from abroad. Thus, the profits of the representative firm read:

$$
\pi_{i}\left(e_{i}\right)=B_{i}\left(e_{i}\right)+p\left(\omega_{i}-e_{i}\right), \quad i=1,2,
$$

where $p$ is the price of permits on an international market. If countries decide against linking, $\omega_{i}=e_{i}$ holds in equilibrium and the second term vanishes.

\subsection{Agency Structure}

In each country $i$ there is a principal whose utility is given by:

$$
V_{i}=\pi_{i}\left(e_{i}\right)-\theta_{i, P} D_{i}(E) .
$$

Without loss of generality, we normalize $\theta_{i, P}$ to unity. In addition, there is a continuum of agents of mass one in each country $i$, whose utilities are given by:

$$
W_{i}=\pi_{i}\left(e_{i}\right)-\theta_{i} D_{i}(E)
$$


where $\theta_{i}$ is a preference parameter that is continuously distributed on the bounded interval $\left[\theta_{i}^{\min }, \theta_{i}^{\max }\right]$. We assume that the boundaries $\theta_{i}^{\min }$ and $\theta_{i}^{\max }$ are such that (i) the principals' preferences are represented in the continuum of agents, i.e., $1 \in\left[\theta_{i}^{\min }, \theta_{i}^{\max }\right]$, and (ii) the principal can always find her preferred agent within the continuum of agents.

In each country, all agents and the principal have equal stakes in the profits of the domestic firm but differ with respect to environmental damages. ${ }^{7}$ This may be either because damages are heterogeneously distributed or because the monetary valuation of homogenous physical environmental damage differs. We assume that all individuals (principals and agents) are selfish in the sense that they maximize their respective utilities, i.e., the principal in country $i$ chooses her actions to maximize $V_{i}$, while each agent in country $i$ makes decisions to maximize his utility $W_{i}$.

We assume that preference parameters of all individuals are common knowledge. Thus, we abstract from all issues related to asymmetric information. ${ }^{8}$

\subsection{Structure and timing of the game}

We model the hierarchical structure of climate policy as a non-cooperative sequential game. In the first stage, the "choice of regime", the principals in both countries simultaneously determine whether an international permit market is formed. Because countries are sovereign, an international permit market only forms if the principals in both countries consent to doing so. In the second stage, the principals simultaneously select an agent from the continuum of available agents. In stage three, these selected agents simultaneously decide on the number of emission allowances that are distributed to the representative domestic firms. In the final stage, emission permits are traded. The complete structure and timing of the game are summarized as follows:

1. Choice of Regime:

Principals in both countries simultaneously decide whether the domestic permit markets are merged to form an international market.

2. Strategic Delegation:

Principals in both countries simultaneously select an agent.

\footnotetext{
7 This is equivalent to assuming that all agents and the principal equally suffer from environmental damages but have different stakes in firm profits, as dividing by $\theta_{i}$ is just a positive affine transformation of the utility functions.

${ }^{8}$ Although this may seem restrictive at first glance, it is not in the context of our model framework. One principal's incentive to strategically delegate to an agent stems exclusively from the other principal's ability to observe the principal's and agent's preferences. Moreover, the assumption is not unrealistic, as high-level political delegates have, in general, well-known political agendas.
} 


\section{Emission Allowance Choices:}

Selected agents in both countries simultaneously choose the number of emission permits issued to the domestic firms.

4. Permit Trade:

Depending on the regime established in the first stage, emission permits are traded on perfectly competitive domestic or international permit markets.

Despite being highly stylized, this model captures essential characteristics of the hierarchical structure of domestic and international environmental policy. As we discuss in greater detail in Section 7, the structure of the model is compatible with various delegation mechanisms present in modern societies. For example, the principal might be the median voter of the electorate while the agent represents the elected government. Alternatively, the principal might be the parliament that delegates a decision to an agent, for example, to the minister of the environment.

We solve the game by backward induction. Therefore, we first determine the equilibrium levels of emission permits for the two different regimes, which depend on the preferences of the selected agents in both countries. Second, we determine the preferences of the agents whom the principals select. Finally, we analyse under which conditions the principals in both countries consent to the formation of an international permit market and compare this to the case when there is no possibility for the principals to delegate strategically.

\section{Permit market equilibrium and delegated permit choice}

In the last stage and in the case of domestic emission permit markets, the market clearing condition implies that $\omega_{i}=e_{i}$ for both countries $i=1,2$. Profit maximization of the representative firm leads to an equalization of marginal benefits with the country-specific equilibrium permit price $p_{i}$ :

$$
p_{i}\left(\omega_{i}\right)=B_{i}^{\prime}\left(e_{i}\right)=\frac{\epsilon_{i}-\omega_{i}}{\phi_{i}}, \quad i=1,2 .
$$

In the case of an international permit market, there is only one permit market price, which implies that, in equilibrium, the marginal benefits of all participating countries are equalized:

$$
p(E)=B_{1}^{\prime}\left(e_{1}(E)\right)=B_{2}^{\prime}\left(e_{2}(E)\right)=\frac{\epsilon_{i}-e_{i}(E)}{\phi_{i}} .
$$


In addition, the market clearing condition:

$$
\omega_{1}+\omega_{2}=B_{1}^{\prime-1}(p(E))+B_{2}^{\prime-1}(p(E))=e_{1}(E)+e_{2}(E)=E
$$

implicitly determines the permit price $p(E)$ in the market equilibrium as a function of the total number of issued emission allowances $E$ :

$$
p(E)=\frac{\epsilon-E}{\phi} .
$$

Equations (7) and (9) also imply:

$$
p^{\prime}(E)=p^{\prime}=\frac{B_{1}^{\prime \prime} B_{2}^{\prime \prime}}{B_{1}^{\prime \prime}+B_{2}^{\prime \prime}}=-\frac{1}{\phi}<0, \quad e_{i}^{\prime}(E)=e_{i}^{\prime}=\frac{B_{-i}^{\prime \prime}}{B_{i}^{\prime \prime}+B_{-i}^{\prime \prime}}=\frac{\phi_{i}}{\phi} \in(0,1) .
$$

Naturally, the permit price goes down as global supply increases, and this increase is absorbed by both countries.

\subsection{Delegated permit choice under a domestic permit market}

In case no international permit market has been formed in the first stage of the game, the selected agent from country $i$ sets the level of emission permits $\omega_{i}$ to maximize: ${ }^{9}$

$$
W_{i}^{D}=B_{i}\left(\omega_{i}\right)-\theta_{i} D_{i}(E)
$$

subject to equation (6) and given the permit choice $\omega_{-i}$ of the other country. Then, the reaction function of the selected agent $i$ is implicitly given by:

$$
B_{i}^{\prime}\left(\omega_{i}\right)-\theta_{i} D_{i}^{\prime}=0
$$

implying that the selected agent in country $i$ trades off the marginal benefits of issuing more permits against the corresponding environmental damage costs. The following proposition holds:

\section{Proposition 1 (Unique NE in stage three under domestic permit markets)}

For any given vector $\Theta=\left(\theta_{1}, \theta_{2}\right)$ of preferences of the selected agents under domestic permit markets, there exists a unique Nash equilibrium of the subgame beginning in stage three, in which all countries $i=1,2$ simultaneously set emission permit levels $\omega_{i}$ to maximize (11) subject to equation (6) and taking the permit level $\omega_{-i}$ of the other country as given.

The proofs of all propositions and corollaries are relegated to the Appendix.

\footnotetext{
${ }^{9}$ Superscript " $D$ " means "domestic", indicating the regime in which only domestic permit markets exist.
} 
We denote the Nash equilibrium of the subgame beginning in stage three by $\Omega^{D}(\Theta)=$ $\left(\omega_{1}^{D}(\Theta), \omega_{2}^{D}(\Theta)\right)$ and the global emission level in this equilibrium by $E^{D}(\Theta)$. For later use, we analyse how the equilibrium emission levels change with a marginal change in the preferences of the selected agent in country $i$.

Corollary 1 (Stage three comparative statics under domestic permit markets) The following conditions hold for the levels of national emissions $\omega_{i}^{D}, \omega_{-i}^{D}$ and total emissions $E^{D}$ in the Nash equilibrium $\Omega^{D}(\Theta)$ :

$$
\frac{d \omega_{i}^{D}(\Theta)}{d \theta_{i}}<0, \quad \frac{d \omega_{-i}^{D}(\Theta)}{d \theta_{i}}=0, \quad \frac{d E^{D}(\Theta)}{d \theta_{i}}<0 .
$$

Corollary 1 states that domestic emission levels $\omega_{i}^{D}$ of country $i$ and global emissions $E^{D}$ are lower in equilibrium when the preference parameter $\theta_{i}$ is higher, i.e., when country $i$ 's selected agent cares more about the environment. Moreover, permit choices are dominant strategies due to the linearity of the damage function.

\subsection{Delegated permit choice under an international permit market}

If an international permit market is formed in the first stage, country $i$ 's selected agent chooses $\omega_{i}$ to maximize: ${ }^{10}$

$$
W_{i}^{I}=B_{i}\left(e_{i}(E)\right)+p(E)\left[\omega_{i}-e_{i}(E)\right]-\theta_{i} D_{i}(E)
$$

subject to equations $(7)$ and (8) and given $\omega_{-i}$. Taking into account that $p(E)=B_{i}^{\prime}\left(e_{i}(E)\right)$, the reaction function of the agent in country $i$ is given by:

$$
p(E)+p^{\prime}\left[\omega_{i}-e_{i}(E)\right]-\theta_{i} D_{i}^{\prime}=0 .
$$

Again, there exists a unique Nash equilibrium of the subgame beginning at stage three:

\section{Proposition 2 (Unique NE in stage three under international permit markets)}

For any given vector $\Theta=\left(\theta_{1}, \theta_{2}\right)$ of preferences of the selected agents under an international permit market, there exists a unique Nash equilibrium of the subgame beginning at stage three, in which both countries simultaneously set the levels of emission permits $\omega_{i}$ to maximize (14) subject to equations (7) and (8) and taking the permit level $\omega_{-i}$ of the other country as given.

${ }^{10}$ Superscript "I" means "international", indicating the regime in which an international permit market is formed. 
Denote the Nash equilibrium by $\Omega^{I}(\Theta)=\left(\omega_{1}^{I}(\Theta), \omega_{2}^{I}(\Theta)\right)$ and the global equilibrium emissions by $E^{I}(\Theta)$. Then, by summing up the reaction functions for both countries, we obtain the equilibrium permit price $p\left(E^{I}(\Theta)\right)$, which is equal to the average marginal environmental damage costs of the selected agents:

$$
p\left(E^{I}(\Theta)\right)=\frac{1}{2}\left[\theta_{i} D_{i}^{\prime}+\theta_{-i} D_{-i}^{\prime}\right] .
$$

Inserting the equilibrium price $p\left(E^{I}(\Theta)\right)$ back into the reaction function (15) yields:

$$
\omega_{i}-e_{i}(E)=\frac{1}{2 p^{\prime}}\left[\theta_{i} D_{i}^{\prime}-\theta_{-i} D_{-i}^{\prime}\right]
$$

revealing that, in equilibrium, the country whose agent exhibits above-average marginal damages is the permit buyer, whereas the country whose agent's marginal damages are below average is the permit seller.

Again, we analyse the influence of the selected agents' preferences on the equilibrium permit choices:

\section{Corollary 2 (Stage three comparative statics under int'l permit markets)}

The following conditions hold for the levels of emission allowances $\omega_{i}^{I}, \omega_{-i}^{I}$ and total emissions $E^{I}$ in the Nash equilibrium $\Omega^{I}(\Theta)$ :

$$
\frac{d \omega_{i}^{I}(\Theta)}{d \theta_{i}}<0, \quad \frac{d \omega_{-i}^{I}(\Theta)}{d \theta_{i}}>0, \quad \frac{d E^{I}(\Theta)}{d \theta_{i}}<0
$$

As before, an increase in $\theta_{i}$ decreases the equilibrium permit level $\omega_{i}^{I}$ and overall emissions, but, in contrast to the domestic permit markets regime, this increases the equilibrium allowance choice $\omega_{-i}^{I}$ of the other country, i.e., the international permit market renders countries' permit choices strategic substitutes. Furthermore, note that domestic emissions are not equal to domestic allowance choices. In fact, equilibrium emissions decrease in both countries if $\theta_{i}$ increases in one of the countries, as a reduction in total emission permits increases the equilibrium permit price; see equation (10).

\section{Strategic delegation}

We now turn to the selection of agents by the principals in the second stage of the game. We assume that the bounds $\theta_{i}^{\min }$ and $\theta_{i}^{\max }$, which determine the minimum and maximum preference parameters of agents to whom the principals can delegate, are such that principals can always find an agent with their preferred preferences. 


\subsection{Strategic delegation under domestic permit markets}

First, assume a domestic permit market regime. Then, the principal in country $i$ selects an agent with preferences $\theta_{i}$ such that

$$
V_{i}^{D}=B_{i}\left(\omega_{i}^{D}(\Theta)\right)-D_{i}\left(E^{D}(\Theta)\right)
$$

is maximized given the Nash equilibrium $\Omega^{D}(\Theta)$ of the subgame beginning in the third stage and the preferences $\theta_{-i}$ of the selected agent in the other country. We derive the following first-order condition:

$$
B_{i}^{\prime}\left(\omega_{i}^{D}(\Theta)\right) \frac{d \omega_{i}^{D}(\Theta)}{d \theta_{i}}-D_{i}^{\prime} \frac{d E^{D}(\Theta)}{d \theta_{i}}=0
$$

which implicitly determines the best-response function $\theta_{i}^{D}\left(\theta_{-i}\right)$.

Taking into account the equilibrium of the third stage, in particular equation (12), we rewrite the first-order condition to yield:

$$
\left(1-\theta_{i}\right) D_{i}^{\prime} \frac{d E^{D}(\Theta)}{d \theta_{i}}=-B_{i}^{\prime}\left(\omega_{i}^{D}(\Theta)\right) \frac{d \omega_{-i}^{D}(\Theta)}{d \theta_{i}}=0
$$

This states that, in equilibrium, the marginal costs of strategic delegation have to equal its marginal benefits. The costs of choosing an agent with lower environmental preferences (left-hand side) are given by the additional (compared to $\theta_{i, P}=1$ ) marginal damage caused by the increase in total emissions. Benefits from strategic delegation (right-hand side) accrue if the principal can pass on some of the abatement burden to the other country. This holds if permit choices in the third stage are strategic substitutes, i.e., $d \omega_{-i}^{D}(\Theta) / d \theta_{i}>0$. In case of domestic permit markets and constant marginal damages, permit choices in the third stage are dominant strategies and, thus, the right-hand side of equation (21) is zero. As a result, the above condition is only satisfied if $\theta_{i}=1$. Hence, there is no incentive for the principal to strategically delegate and the subgame beginning in stage two exhibits a unique subgame perfect Nash equilibrium in which principals choose $\theta_{i}^{D}=1$. We refer to this case as self-representation.

\section{Proposition 3 (Unique NE in stage two under domestic permit markets)}

Given a domestic permit market regime, the subgame beginning at stage two, in which the principals of both countries $i=1,2$ simultaneously select agents with preferences $\theta_{i}$ to maximize (19) subject to $\Omega^{D}(\Theta)$ and given the choice $\theta_{-i}$ of the principal in country $-i$ exhibits a unique subgame perfect Nash equilibrium, in which principals represent themselves, i.e., $\Theta^{D}=\left(\theta_{1}^{D}, \theta_{2}^{D}\right)=(1,1)$. 


\subsection{Strategic delegation under an international permit market}

Now assume an international permit market regime. Then, the principal in country $i$ selects an agent with preferences $\theta_{i}$ to maximize

$$
V_{i}^{I}=B_{i}\left(e_{i}\left(E^{I}(\Theta)\right)\right)+p\left(E^{I}(\Theta)\right)\left[\omega_{i}^{I}(\Theta)-e_{i}\left(E^{I}(\Theta)\right)\right]-D_{i}\left(E^{I}(\Theta)\right)
$$

given the Nash equilibrium $\Omega^{I}(\Theta)$ of the subgame beginning in the third stage and the preferences $\theta_{-i}$ of the selected agent in the other country. Now, the first-order condition reads:

$$
p\left(E^{I}(\Theta)\right) \frac{d \omega_{i}^{I}(\Theta)}{d \theta_{i}}+\left\{p^{\prime}\left[\omega_{i}^{I}(\Theta)-e_{i}\left(E^{I}(\Theta)\right)\right]-D_{i}^{\prime}\right\} \frac{d E^{I}(\Theta)}{d \theta_{i}}=0
$$

which implicitly defines the best-response function $\theta_{i}^{I}\left(\theta_{-i}\right)$. Compared to the case of domestic permit markets, an additional term enters the principals' trade-off due to the terms of trade on the international permit market. Again, we re-write the first-order condition by taking into account the equilibrium in the third stage, in particular equation (15):

$$
\left(1-\theta_{i}\right) D_{i}^{\prime} \frac{d E^{I}(\Theta)}{d \theta_{i}}=-p\left(E^{I}(\Theta)\right) \frac{d \omega_{-i}^{I}(\Theta)}{d \theta_{i}} .
$$

Similarly to equation (21), this equation says that, in equilibrium, the marginal costs of strategic delegation have to equal its marginal benefits, but now the marginal benefits are non-zero. The intuition is that due to the strategic substitutability of permit choices, part of the abatement effort can - ceteris paribus - be passed on to the other country. The marginal benefits are, thus, given by the marginal production benefits (of having to abate less) which are equal across countries and given by the uniform permit price $p$, times the decrease in the number of permits that the other country issues. There exists a unique subgame perfect Nash equilibrium of the subgame beginning at stage two:

\section{Proposition 4 (Unique NE in stage two under international permit markets)}

Given an international permit market regime, there exists a unique subgame perfect Nash equilibrium of the subgame beginning at stage two, in which the principals of both countries $i=1,2$ simultaneously select agents with preferences $\theta_{i}$ to maximize $(22)$ subject to $\Omega^{I}(\Theta)$ and given the choice $\theta_{-i}$ of the principal in country $-i$.

The following corollary characterizes the properties of the subgame perfect Nash equilibrium:

Corollary 3 (Properties of NE under international permit markets)

For the unique Nash equilibrium $\Theta^{I}$, the following conditions hold: 
1. The principals of both countries choose $\theta_{i}^{I}<1$.

2. Principal $i$ delegates more strongly, i.e., chooses an agent with lower preference parameter $\theta_{i}$, the lower are her marginal damages and the less her marginal benefits decrease. In particular, it holds that

$$
\theta_{i}^{I}<\theta_{-i}^{I} \quad \Leftrightarrow \quad \frac{\delta_{i}}{\phi_{i}}<\frac{\delta_{-i}}{\phi_{-i}}
$$

3. If the condition

$$
\frac{\delta_{i}}{\delta_{-i}}<\frac{\phi_{i}}{2 \phi_{i}+3 \phi_{-i}}<\frac{1}{2}
$$

holds, then the principal in country $i$ delegates to an agent with a negative preference parameter $\theta_{i}^{I}<0$.

Corollary 3 implies that, in the case of an international permit market, self-representation $\left(\theta_{i}^{I}=1\right)$ can never be an equilibrium outcome, as the interaction through the permit market ensures that permit choices in stage three of the game are strategic substitutes. In other words, the principals in both countries attempt to shift the burden of emissions abatement to the other country by delegating the choice of emission permits to agents who value environmental damages strictly less than they do themselves $\left(\theta_{i}^{I}<1\right)$.

The principals delegate more strongly, i.e., they choose an agent with lower $\theta_{i}$, the lower are their marginal damages and the less their marginal benefits fall. The intuition for the former result is that the principals' willingness to tolerate higher global emissions rises with lower marginal damages. As a result, an agent with lower $\theta_{i}$, who will issue more domestic permits and thereby increase global emissions, can be chosen. If marginal benefits fall less steeply, the principal enjoys higher marginal benefits from choosing a lower $\theta_{i}$ because her country will now absorb a bigger share of the additional permits issued by the less green agent; see equation (10). As a consequence, the principal in one country will also delegate more strongly than her counterpart in the other country if her marginal damages are lower and the production benefits fall by less than in the other country.

The incentive to strategically delegate may be so strong for one country that the principal prefers to empower an agent with a negative preference parameter $\theta_{i}$, which implies that the agent perceives environmental damages as a benefit. This happens whenever one principal's marginal damages are sufficiently small compared to the other principal's marginal damages (a necessary condition is that they are less than one half). 
Previous studies analysed strategic delegation under either an environmental tax or an environmental standard (e.g., Siqueira 2003; Buchholz et al. 2005; Roelfsema 2007). They also found that, with perfect pollution spillovers as in our model, principals delegate in equilibrium to agents that are less green than they are themselves. However, in these papers this result crucially depends on the assumption of increasing marginal damages, which induce strategic substitutability among the agents' policy choices. One of our main contributions in this paper is to show that even with constant marginal damages strategic delegation will occur in case of an international permit market.

\section{Formation of international emission permit markets}

We now turn to the first stage of the game and the question which permit market regime $R \in$ $\{D, I\}$ will be established. To answer this question, we first examine the circumstances under which the principals in both countries consent to the formation of an international permit market. Then, we discuss how strategic delegation induces less favourable circumstances for an international emission permit market to form.

\subsection{The choice of regime}

Recall that an international permit market only forms if it is in the best interest of the principals in both countries. In considering their preferred regime choices, the principals in both countries anticipate the influence of the regime choice on the outcomes of the following stages. Thus, principals are aware that the regime choice $R \in\{D, I\}$ in the first stage induces preference parameters for the selected agents given by $\Theta^{R}$ and emission allowance choices of $\Omega^{R}\left(\Theta^{R}\right)$. The principal in country $i$ prefers an international emission permit market if her utility difference between the international and the domestic permit market regime - given the subgame perfect Nash equilibria of the second and third stages of the game under the respective regime - is strictly positive. Formally, this implies:

$$
\begin{aligned}
\Delta V_{i} \equiv & B_{i}\left(e_{i}\left(E^{I}\left(\Theta^{I}\right)\right)\right)-B_{i}\left(\omega_{i}^{D}\left(\Theta^{D}\right)\right)+p\left(E^{I}\left(\Theta^{I}\right)\right)\left[\omega_{i}^{I}\left(\Theta^{I}\right)-e_{i}\left(E^{I}\left(\Theta^{I}\right)\right)\right] \\
& -\theta_{i}^{M}\left[D_{i}\left(E^{I}\left(\Theta^{I}\right)\right)-D_{i}\left(E^{D}\left(\Theta^{D}\right)\right)\right]>0
\end{aligned}
$$


Then, an international permit market forms if and only if it is a Pareto improvement for the principals compared to domestic permit markets: ${ }^{11}$

$$
\Delta V_{i}>0 \wedge \Delta V_{-i}>0
$$

\subsection{Formation of international permit markets in the absence of delegation}

It is illustrative to first show under which circumstances an international permit market forms in the absence of delegation. For this case, equation (27) yields:

$$
\begin{aligned}
\Delta V_{i} & =V_{i}^{I}\left(\Theta_{P}\right)-V_{i}^{D}\left(\Theta_{P}\right) \\
& =\frac{1}{8}\left(\delta_{-i}-\delta_{i}\right)\left[\phi_{i}\left(\delta_{-i}+\delta_{i}\right)+2 \phi_{i} \delta_{i}+2 \phi_{-i}\left(\delta_{-i}-\delta_{i}\right)\right],
\end{aligned}
$$

where $\Theta_{P}=\left(\theta_{1, P}, \theta_{2, P}\right)=(1,1)$ implies that principals choose agents with the same preferences as their own. Without loss of generality, assume that country $i$ exhibits lower marginal damages, i.e., $\delta_{i}<\delta_{-i}$. According to equation (17), this implies that country $i$ is the permit seller in case of an international permit market regime. Then the payoff difference as measured by (29) is always strictly positive. In other words, the permit seller always prefers the international permit market to domestic permit markets. But what if $i$ were the permit buyer, i.e., $\delta_{i}>\delta_{-i}$ ? In this case, a necessary (but not sufficient) condition for principal $i$ to support an international permit market is that $\phi_{i}<\phi_{-i}$, i.e., $i$ 's marginal benefits fall by more than $-i$ 's marginal benefits. In addition, whenever an international permit market forms, global emissions are lower compared to a domestic permit market regime. We summarize this finding in the following proposition.

\section{Proposition 5 (Conditions for a permit market to form without delegation)}

In the absence of delegation, a necessary condition for an international permit market to form is that the country with the higher carbon efficiency also exhibits higher marginal environmental damages:

$$
\phi_{i}<\phi_{-i} \wedge \delta_{i}>\delta_{-i}
$$

Under these conditions, global emissions are also lower in the international permit market regime compared to the domestic permit market regime.

\footnotetext{
${ }^{11}$ We assume that country $i$ 's principal only favours an international permit market over domestic permit markets if $\Delta V_{i}$ is strictly positive. The intuition behind this tie-breaking rule is the assumption that domestic permit markets represent the status quo. If linking domestic permit markets to an international market induces some positive costs $\epsilon$, then $\Delta V_{i}>\epsilon>0$ has to hold for an international permit market to be favourable. However, this tie-breaking rule does not qualitatively affect our results, and any other tie-breaking rule is permissible.
} 
Proposition 5 states that an international permit market will (if at all) only form if we match a country with high carbon efficiency and high willingness to pay for abating environmental damages to a country with low carbon efficiency and low willingness to pay. However, whenever an international permit market forms, it is a win-win situation in the sense that, compared to a domestic permit market regime, it is (i) a Pareto improvement from the principals' point of view and (ii) global emissions are lower.

\subsection{Formation of international permit markets in the presence of delegation}

In case of strategic delegation, the payoff difference for the principal in country $i$ reads:

$$
\begin{aligned}
\Delta V_{i} & =V_{i}^{I}\left(\Theta^{I}\right)-V_{i}^{D}\left(\Theta^{D}\right) \\
& =\frac{1}{18}\left[\delta_{i}^{2}\left(2 \phi_{-i}-6 \phi_{i}\right)+\delta_{i} \delta_{-i}\left(6 \phi_{i}-14 \phi_{-i}\right)+\delta_{-i}^{2}\left(3 \phi_{i}+2 \phi_{i}\right)\right] .
\end{aligned}
$$

Note that $\Theta^{D}=\Theta_{P}=(1,1)$ and, thus, the second term in the first line of equation (31) is identical to the second term of equation (29). Therefore, the possibility of delegation only changes the principal's welfare in case of an international emission permit market. In fact, strategic delegation renders the formation of an international permit market less likely, as the following proposition states:

\section{Proposition 6 (Effect of delegation on formation of int'l permit market)}

Strategic delegation renders the formation of an international permit market less likely in the following sense:

1. It cannot happen that an international permit market forms under strategic delegation while it would not have formed without delegation.

2. It can happen that an international permit market regime constitutes a Pareto improvement for the principals over a domestic permit market regime without delegation but is not a Pareto improvement in case of strategic delegation.

To prove Proposition 6, we first show that in case condition (30) holds, the permit buyer, who is pivotal for the formation of an international permit market in the absence of delegation, loses under strategic delegation and, therefore, is less likely to consent to the formation of an international permit market. In addition, we show that it cannot happen that an international permit market forms under strategic delegation while it would not have formed without delegation. Together, this implies that strategic delegation leads to less favourable conditions, compared to the situation without delegation, for an international emission permit market to be a Pareto improvement. 
Note that condition (30) is a necessary condition for an international permit market to be mutually beneficial in both cases, with and without delegation. As a consequence, we can restrict attention to cases where condition (30) holds. Under these circumstances, the principal of country $-i$, who values environmental damages less (i.e., $\delta_{-i}<\delta_{i}$ ) delegates more strategically (i.e., $\theta_{-i}^{I}<\theta_{i}^{I}$ ) in the subgame perfect Nash equilibrium of the international permit market with delegation, according to Corollary 3 part two. This also implies that $\theta_{-i} \delta_{-i}<\theta_{i} \delta_{i}$. Thus, the roles of permit seller and permit buyer in the subgame perfect Nash equilibrium in case of an international permit market regime do not change because of delegation. That is, in case of an international permit market, if a country is the permit seller in the absence of delegation, it is also the permit seller in the presence of strategic delegation.

Finally, we investigate how global emissions under an international permit market with strategic delegation compare to global emissions under a domestic permit market regime. The following proposition states the results:

\section{Proposition 7 (Global emissions under int'l permit market with delegation)}

In equilibrium the following statements hold:

1. Under an international permit market, global emissions are strictly higher with strategic delegation than without.

2. A necessary condition for an international permit market with delegation to be mutually beneficial for the principals in both countries is that global emissions under the international permit market regime are lower than under a domestic permit market regime.

Proposition 7 provides a straightforward intuition why strategic delegation leads to less favourable circumstances for an international permit market to form. First, everything else equal, strategic delegation increases the equilibrium emissions under an international permit market regime. Second, as lower global emissions compared to the domestic permit market regime are a necessary condition for the formation of an international permit market, strategic delegation reduces the parameter space for which an international permit market regime is a Pareto improvement from the principals' perspective.

\section{Numerical Illustration}

We illustrate our main findings with a numerical example. As discussed in Section 5, condition (30) is a necessary condition for an international permit market to be mutually beneficial in both cases, with and without delegation of permit choices. Consequently, we 
Without strategic delegation

\begin{tabular}{|c|cc|ccccc|cc|}
\hline Regime & $\theta_{1}^{R}$ & $\theta_{2}^{R}$ & $\omega_{1}^{R}$ & $\omega_{2}^{R}$ & $e_{1}^{R}$ & $e_{2}^{R}$ & $E^{R}$ & $V_{1}^{R}$ & $V_{2}^{R}$ \\
\hline$R=D$ & 1 & 1 & 2.87 & 0.94 & & & 3.81 & 4.42 & 2.70 \\
$R=I$ & 1 & 1 & 2.89 & 0.74 & 2.66 & 0.96 & 3.63 & 4.48 & 2.73 \\
\hline
\end{tabular}

With strategic delegation

\begin{tabular}{|c|cc|ccccc|cc|}
\hline Regime & $\theta_{1}^{R}$ & $\theta_{2}^{R}$ & $\omega_{1}^{R}$ & $\omega_{2}^{R}$ & $e_{1}^{R}$ & $e_{2}^{R}$ & $E^{R}$ & $V_{1}^{R}$ & $V_{2}^{R}$ \\
\hline$R=D$ & 1 & 1 & 2.87 & 0.94 & & & 3.81 & 4.42 & 2.70 \\
$R=I$ & -0.50 & 0.96 & 3.1 & 0.65 & 2.78 & 0.98 & 3.75 & 4.49 & 2.67 \\
\hline
\end{tabular}

Table 1: Overview of the outcomes in the subgame perfect Nash equilibria without and with strategic delegation for the numerical example detailed in the Appendix.

choose parameter constellations such that one country (or country block) exhibits a low carbon efficiency (which is equivalent to low marginal abatement costs), i.e., a high $\phi_{i}$, and its principal a low willingness to pay (WTP) to prevent environmental damages, i.e., a low $\delta_{i}$, and the second country has a high carbon efficiency and its principle a high WTP to prevent environmental damages, i.e., low $\phi_{-i}$ and high $\delta_{-i}$. One can think of the former country (henceforth country 1) as a country in transition, while country 2 represents a developed country.

We calibrate the example to China (country 1) and the European Union (country 2), using relative energy productivities taken from the OECD Green Growth Indicators database as a proxy for carbon efficiencies and using relative WTPs based on the estimates provided in Carlsson et al. (2012). Details of the calibration are given in the Appendix. The results are illustrated in Table 1. Without delegation, an international permit market comes into existence, as the principals of both the EU and China have higher payoffs under an international permit market regime than under domestic permit markets. Furthermore, China is the seller of emission permits, which is in line with findings from Carbone et al. (2009). The EU, being the high-damage country block, benefits from both an overall decrease in total emissions and a decrease in marginal abatement costs.

In the case of strategic delegation, nothing changes under domestic permit markets, as the principles in both countries have no incentive to strategically delegate. This is also evident in Figure 1, which depicts the reaction functions from the delegation stage for the principals in both countries. The reactions functions in case of the domestic permit market regime are constant at one. In the case of an international permit market, however, the delegation incentives for the permit-selling country are much stronger than those for the permit-buying country, as stated in Corollary 3 and shown in Figure 1. The principal of country 1 (China), even delegates to an agent with negative environmental preferences, i.e., an agent who perceives climate change as a benefit. By doing so, the number of emission permits issued in 


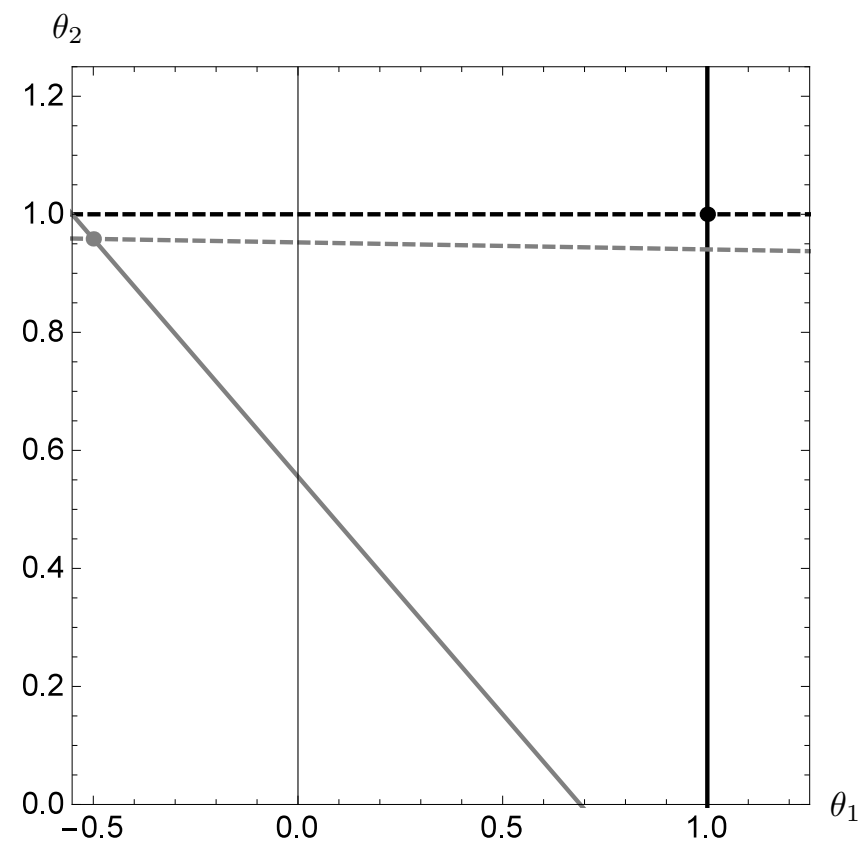

Figure 1: Reaction functions of the principals in country 1 (China, solid) and country 2 (EU, dashed) under the regimes $R=D$ (black) and $R=I$ (gray) at the delegation stage.

China rises notably compared to self-representation, whereas the EU decreases the number of permits compared to self-representation. Overall emissions rise under strategic delegation relative to self-representation in the case of an international permit market. While the principal of country 1 still prefers an international permit market regime, the principal of the other country is better off under domestic permit markets. In contrast to the case of self-representation, no international market will emerge.

This example highlights that, while the formation of an international permit market may be beneficial for all principals if they represent themselves, this is less likely to be the case under strategic delegation. The reason is that there are incentives to delegate to less green agents under an international permit market which are absent in case of domestic permit markets. This commitment by the principals leads to higher aggregate emissions and makes the principal of the high-damage country (the EU) less inclined to consent to the formation of an international permit market.

\section{Discussion}

Our explicit discussion of the hierarchical structure of international environmental policies may shed light on the puzzle of why we have yet to witness the formation of many 
non-cooperative international permit markets. The advantage of an international permit market, in which individual countries non-cooperatively determine permit issuance, over non-cooperative domestic environmental policies is the equalization of marginal benefits from emissions across all countries, which is a necessary condition for efficiency. However, from the principals' perspective, the efficiency gains from equalizing marginal benefits across countries come at the additional cost of strategic delegation, i.e., the incentive to delegate the emission permit choice to agents who have a lower valuation for the environment than they have themselves. As this incentive is absent under a domestic permit market regime, there is an additional trade-off favouring the domestic permit market regime, which has been overlooked in the standard non-cooperative permit market setting.

Our analytical derivation of results hinges on the particular functional forms we assumed for the benefit and damage functions; see equations (1). In particular, the assumption of constant marginal damages may seem restrictive. The reason for this assumption is twofold: First, it allows for an analytical solution of the subgame perfect Nash equilibria. Second, constant marginal damages pose the least favourable conditions for strategic delegation to occur, as permit choices are dominant strategies in case of domestic permit markets. Yet, we show that strategic delegation still occurs in the case of an international permit market. In addition, our assumptions of quadratic benefits and linear damages are not unrealistic. Klepper and Peterson (2006) show that abatement cost curves (which, in our model, correspond to the benefits of unabated emissions) can well be approximated by quadratic functions. The linear damage specification is in line with the assumptions made in complex integrated assessment or general equilibrium climate-economy models (see, e.g., Nordhaus and Boyer 2000, Golosov et al. 2014), in which climate damage is approximately linear in the GHG concentration in the atmosphere. This is because, typically, temperature is assumed to increase logarithmically with concentrations, whereas damage is assumed to be exponential or polynomial in temperature. ${ }^{12}$ Finally, our results are qualitatively robust to strictly convex damage specifications. In fact, we discuss the case of sufficiently quadratic benefit and damage functions in detail in Habla and Winkler (2016).

We analyse a particular environmental policy in our model: emission permit markets. However, our results do not hinge on the domestic policy being an emissions permit scheme, which we chose for analytical convenience. They would still hold if we considered domestic emission tax schemes instead, because without uncertainty price and quantity regulations are equivalent. In addition, whether permits are grandfathered or auctioned is inconsequential in our model, as firm profits accrue to the individual agents in the respective countries.

12 See also Burke et al. (2015) as one of the very few empirical papers estimating macroeconomic damages due to temperature increases. They find that damages, measured as deviations of economic productivity from a country-specific temperature optimum, are convex in temperature. 
In the case of grandfathering, endowing firms with permits for free implies higher profits for the firms and, thus, higher income for the individual agents, whereas in the case of auctioning, the revenues from the auction directly accrue to the individual agents, for example, in the form of a lump-sum transfer.

Despite our highly stylized, four-stage principal-agent model, we argue that both the timing of the game and the delegation procedure are compatible with different principal-agent relationships that arise in the hierarchical policy procedures of modern societies. We wish to illustrate this claim with two examples. First, assume that the principal is the median voter and the agent is an elected government. ${ }^{13}$ Then, the four-stage game translates into the following sequence of events. In stage one, the median voter decides on the regime. While this may be unusual in representative democracies, it is rather the rule in direct democracies such as Switzerland, where binary and one-shot decisions are often made by the electorate via referendum. In the second stage, the median voter elects a government that determines the number of allowances issued to the domestic firms in the third stage. Following this interpretation, we have a strategic voting game between the electorate and the elected government.

Second, assume that the principal is the parliament of a representative democracy and the agent is, for example, the minister of environment. Now, the parliament determines the regime in the first stage. In the second stage, it elects the executive, for example, the minister of environment, who then determines the number of emission allowances in the third stage. While it is rather unusual that the parliament, i.e., the legislature, elects the executive, this is, for example, the case in Germany.

Although the structure and timing of our principal-agent game is consistent with realworld hierarchical decision-making procedures, there is a more general interpretation of the principal-agent relationship in our game setting. Because of the strategic interaction at the international level, the principals in both countries have an incentive to commit to a less green policy in order to free-ride on the abatement efforts of the other country which arises due to the strategic substitutability of emission permit choices under an international permit market regime. However, principals need a credible commitment device, as the equilibrium permit choice under strategic delegation is at odds with their own preferences. The strategic delegation framework in our model provides such a commitment device that enables the principal to credibly pursue a less green environmental policy. Yet, any other credible commitment device, such as investments in adaptation to climate change or

\footnotetext{
${ }^{13}$ For this interpretation, we require that $\theta_{i, P}=1$ is indeed the median in the preference distribution with respect to environmental damages. This can always be achieved by an appropriate normalization. In addition, it is straightforward to show that the voters can be ordered according to the preference parameter $\theta_{i}$, with $\partial \omega_{i} / \partial \theta_{i}<0$. As a consequence, the median voter theorem applies.
} 
in long-lived, emissions-intensive energy infrastructure would result in a similar race to the bottom whereby principals in both countries would issue more emission allowances than would be the case if they could not credibly commit to such a policy. ${ }^{14}$ Thus, our results are qualitatively robust beyond the particular principal-agent relationship considered in our model framework.

Finally, our analysis reveals that principals are not necessarily subjected to the race to the bottom in delegating to agents with less green preferences than they exhibit themselves. In our setting, they have an instrument at their disposal that enables them to defend themselves against strategic delegation and its adverse impacts - they can choose the domestic permit markets regime in which no incentives for strategic delegation exist. We find that a principal makes use of this instrument whenever the costs of strategic delegation outweigh her benefits of establishing an international permit market. It is conceivable that similar instruments exist in other contexts which are able to mitigate the adverse effects of strategic delegation.

\section{Conclusion}

We have analysed the non-cooperative formation of an international permit market in a hierarchical policy framework, in which a principal in each country chooses an agent who is in charge of determining the domestic emissions allowance. We find that the principals in both countries select agents who have (weakly) less green preferences than they have themselves. When emission allowance choices are strategic substitutes, delegation allows the principals to credibly commit to a less green policy and thus shift - ceteris paribus - part of the abatement burden to the other country. This is, for example, the case if an international permit market comes into existence, even for constant marginal damages. At the same time, delegation and its adverse consequences on global emissions make the formation of an international market less likely than under the benchmark case of self-representation.

While our results may explain the reluctance to establish non-cooperative international permit markets, despite their seemingly favourable characteristics, they also constitute the more general warning that treating countries as single welfare-maximizing agents in the international policy arena may be an oversimplification. As a consequence, the analysis of the nexus between domestic and international (environmental) policy seems to be a promising avenue for future research.

\footnotetext{
${ }^{14}$ Copeland (1990), Buchholz and Konrad (1994), Buchholz and Haslbeck (1997) and Beccherle and Tirole (2011) discuss technological choices and investments as commitment devices through which a country can improve its position in negotiations concerning an environmental agreement.
} 


\section{Appendix}

\section{Proof of Proposition 1}

Inserting the market equilibrium condition $e_{i}=\omega_{i}$ into the best response function (12) and solving for $\omega_{i}$ yields dominant strategies for each country $i$ which, together, constitute the unique Nash equilibrium:

$$
\omega_{i}^{D}(\Theta)=\epsilon_{i}-\theta_{i} \phi_{i} \delta_{i} .
$$

Global emissions are then given by:

$$
E^{D}(\Theta)=\epsilon-\left(\theta_{i} \phi_{i} \delta_{i}+\theta_{-i} \phi_{-i} \delta_{-i}\right) .
$$

\section{Proof of Corollary 1}

Conditions (13) follow directly from equations (A.1) and (A.2):

$$
\begin{aligned}
\frac{\partial \omega_{i}^{D}(\Theta)}{\partial \theta_{i}} & =-\phi_{i} \delta_{i}<0, \\
\frac{\partial \omega_{-} i^{D}(\Theta)}{\partial \theta_{i}} & =0, \\
\frac{\partial E^{D}(\Theta)}{\partial \theta_{i}} & =-\phi_{i} \delta_{i}<0 .
\end{aligned}
$$

\section{Proof of Proposition 2}

Recall that the equilibrium permit market price $p\left(E^{I}(\Theta)\right)$ is given by:

$$
p\left(E^{I}(\Theta)\right)=\frac{1}{2}\left(\theta_{i} \delta_{i}+\theta_{-i} \delta_{-i}\right) .
$$

Inserting into equation (9) yields for the global emission level in the Nash equilibrium:

$$
E^{I}(\Theta)=\epsilon-\frac{1}{2}\left(\theta_{i} \delta_{i}+\theta_{-i} \delta_{-i}\right)
$$

Inserting $p\left(E^{I}(\Theta)\right)$ and $E^{I}(\Theta)$ into the reaction function yields the permit choices in the Nash equilibrium:

$$
\omega_{i}^{I}(\Theta)=\epsilon_{i}+\frac{1}{2} \phi_{-i}\left(\theta_{i} \delta_{i}+\theta_{-i} \delta_{-i}\right)-\phi \theta_{i} \delta_{i} .
$$




\section{Proof of Corollary 2}

Conditions (18) follow directly from equations (A.7) and (A.8):

$$
\begin{aligned}
\frac{\partial \omega_{i}^{I}(\Theta)}{\partial \theta_{i}} & =-\delta_{i}\left(\phi_{i}+\frac{1}{2} \phi_{-i}\right)<0, \\
\frac{\partial \omega_{-i}^{I}(\Theta)}{\partial \theta_{i}} & =\frac{1}{2} \phi_{i} \delta_{i}>0, \\
\frac{\partial E^{I}(\Theta)}{\partial \theta_{i}} & =-\frac{1}{2} \phi \delta_{i}<0 .
\end{aligned}
$$

\section{Proof of Proposition 3}

Taking into account that $d \omega_{-i} / d \theta_{i}=0$, the reaction function (21) reads:

$$
\left(1-\theta_{i}\right) D_{i}^{\prime} \frac{d E^{D}(\Theta)}{d \theta_{i}}=0
$$

As $D_{i}^{\prime}>0$ and $d E^{D}(\Theta) / d \theta_{i}<0$, the equation can only hold if $\theta_{i}=1$. Thus, $\theta_{i}=1$ is a dominant strategy for both principals in case of a domestic permit market regime. As a consequence, there exists a unique subgame perfect Nash equilibrium at stage two of the game in which both principals represent themselves, i.e., $\theta_{i}^{D}=1$.

\section{Proof of Proposition 4}

Using the functional forms (1) for the reaction function (23) yields:

$$
\theta_{i}\left(\theta_{-i}\right)=\frac{2 \phi}{3 \phi_{i}+2 \phi_{-i}}-\theta_{-i} \frac{\phi_{i} \delta_{-i}}{\delta_{i}\left(3 \phi_{i}+2 \phi_{-i}\right)} .
$$

As both reaction functions are decreasing linear functions, they intersect exactly once at:

$$
\theta_{i}^{I}=1-\frac{\phi_{i}\left(\delta_{i}+\delta_{-i}\right)}{3 \delta_{i} \phi}
$$

\section{Proof of Corollary 3}

The first and third property immediately follow from (A.14). To show the second property, 
we differentiate this equation with respect to $\delta_{i}$ and $\phi_{i}$, yielding:

$$
\frac{\partial \theta_{i}^{I}}{\partial \delta_{i}}=\frac{3 \delta_{-i} \phi_{i} \phi}{\left(3 \delta_{i} \phi\right)^{2}}>0, \quad \frac{\partial \theta_{i}^{I}}{\partial \phi_{i}}=-\frac{3 \delta_{i}\left(\delta_{i}+\delta_{-i}\right) \phi_{-i}}{\left(3 \delta_{i} \phi\right)^{2}}<0 .
$$

Comparing (A.14) for $i$ and $-i$, we obtain condition (25), which obviously holds if $\delta_{i}<\delta_{-i}$ and $\phi_{i}>\phi_{-i}$.

\section{Proof of Proposition 5}

While it is obvious from equation (29) that if country $i$ is the permit seller, i.e., $\delta_{i}<\delta_{-i}$, its principal is always strictly better off under an international permit market than under domestic permit markets, this is not necessarily the case if country $i$ is the permit buyer, i.e., $\delta_{i}>\delta_{-i}$. In this case, principal $i$ consents to an international permit market if the following two conditions hold simultaneously:

$$
\frac{\delta_{i}}{\delta_{-i}}<\frac{2 \phi_{-i}+\phi_{i}}{2 \phi_{-i}-3 \phi_{i}} \quad \wedge \quad \frac{\phi_{i}}{\phi_{-i}}<\frac{2\left(\delta_{i}-\delta_{-i}\right)}{3 \delta_{i}+\delta_{-i}}<1 .
$$

As country $-i$ is the permit seller, for an international permit market to form, principal $i$ 's marginal damages must not be too large relative to principal $-i$ 's marginal damages, and, since the term on the right-hand side of the latter inequality is smaller than one, a necessary condition is that $\phi_{i}<\phi_{-i}$.

To show under which condition global emissions are lower under an international permit market regime without delegation, we have to compare (A.2) with (A.7) for $\Theta_{P}=(1,1)$ :

$$
E^{I}\left(\Theta_{P}\right)<E^{D}\left(\Theta_{P}\right) \quad \Leftrightarrow \quad \frac{1}{2}\left(\delta_{i}-\delta_{-i}\right)\left(\phi_{i}-\phi_{-i}\right)<0 .
$$

This condition holds if and only if condition (30) holds.

\section{Proof of Proposition 6}

To prove this proposition, we first add and subtract the principal's payoff under an international permit market under self-representation, $V_{i}^{I}\left(\Theta_{P}\right)$ :

$$
\Delta V_{i}(\Theta)=\left[V_{i}^{I}\left(\Theta_{P}\right)-V_{i}^{D}\left(\Theta^{D}\right)\right]+\left[V_{i}^{I}\left(\Theta^{I}\right)-V_{i}^{I}\left(\Theta_{P}\right)\right] .
$$

Because the principal does not wish to delegate in the case of domestic permit markets, it holds that $V_{i}^{D}\left(\Theta^{D}\right)=V_{i}^{D}\left(\Theta_{P}\right)$. Thus, the first bracketed term in the above equation, which we denote by $\Gamma_{i}^{\text {nodel }}$, is equal to equation (29). For the second bracketed term, which we 
denote by $\Gamma_{i}^{\text {del }}$, we obtain in case of an interior solution:

$$
\Gamma_{i}^{\text {del }}=\frac{1}{72}\left(\delta_{i}+\delta_{-i}\right)^{2}\left(3 \phi_{i}-10 \phi_{-i}\right) \gtreqless 0 \quad \Leftrightarrow \quad \phi_{i} \gtreqless \frac{10}{3} \phi_{-i} .
$$

Second, we distinguish two cases:

(i) Condition (30) holds, i.e., $\delta_{i}>\delta_{-i}, \phi_{i}<\phi_{-i}$. Then, we obtain:

$$
\begin{array}{ll}
\Gamma_{i}^{\text {nodel }} \gtreqless 0, & \Gamma_{i}^{\text {del }}<0, \\
\Gamma_{-i}^{\text {nodel }}>0, & \Gamma_{-i}^{\text {del }} \gtreqless 0 .
\end{array}
$$

Thus, country $i$, which is a permit buyer in case of an international permit market without delegation, is worse off due to delegation, while country $-i$, which is the permit seller without delegation, may gain or lose due to delegation. As the permit buyer (country $i$ ) is pivotal for the formation of an international permit market without delegation, this result implies that strategic delegation makes the formation of an international permit market less likely.

(ii) Suppose that $\delta_{i}>\delta_{-i}, \phi_{i}>\phi_{-i}$. Then, we obtain:

$$
\begin{array}{ll}
\Gamma_{i}^{\text {nodel }}<0, & \Gamma_{i}^{\text {del }} \gtreqless 0, \\
\Gamma_{-i}^{\text {nodel }}>0, & \Gamma_{-i}^{\text {del }}<0 .
\end{array}
$$

Under these conditions, an international permit market would not have formed without delegation, as country $i$, the permit buyer, prefers a domestic permit market regime. However, country $i$ might gain under strategic delegation if $\phi_{i}>10 \phi_{-i} / 3$. In fact, an international permit market can only form in case of delegation if the following two inequalities hold simultaneously:

$$
\Gamma_{i}^{\text {nodel }}+\Gamma_{i}^{\text {del }}>0 \wedge \Gamma_{-i}^{\text {nodel }}+\Gamma_{-i}^{\text {del }}>0 .
$$

This can only hold if:

$$
\Gamma_{i}^{\text {nodel }}+\Gamma_{-i}^{\text {nodel }}>-\left(\Gamma_{i}^{\text {del }}+\Gamma_{-i}^{\text {del }}\right)
$$

Plugging in equations (29) and (A.19), it can be shown that the left-hand side of this inequality is strictly negative while the right-hand side is strictly positive for the assumed parameter constellation, leading to a contradiction. Therefore, the two inequalities (A.22) do not hold simultaneously. As a consequence, it cannot happen that an international permit market regime is established under strategic delegation while it was not to be established without delegation. 


\section{Proof of Proposition 7}

To show the first part, we compare global emissions on an international permit market with and without delegation and obtain:

$$
E^{I}\left(\Theta^{I}\right)-E^{I}\left(\Theta_{P}\right)=\frac{1}{6} \phi\left(\delta_{i}+\delta_{i}\right)>0 .
$$

Thus, delegation leads to higher global emissions in an international permit market regime. For the second part, we compare global emissions between the domestic and the international permit market regime. Global emissions decrease under regime $R=I$ compared to regime $R=D$ if and only if:

$$
E^{D}-E^{I}>0 \Leftrightarrow \phi_{i}\left(\delta_{-i}-2 \delta_{i}\right)+\phi_{-i}\left(\delta_{i}-2 \delta_{-i}\right)>0 .
$$

An international permit market forms if and only if $\Delta V_{i}>0$ and $\Delta V_{-i}>0$ hold simultaneously. A necessary condition, is that $\Delta V_{i}+\Delta V_{-i}>0$ :

$$
\begin{aligned}
\Delta V_{i}+\Delta V_{-i} & =\frac{1}{18}\left[\left(2 \delta_{i}+5 \delta_{-i}\left(\phi_{i} \delta_{-i}-2 \phi_{i} \delta_{i}\right)+\left(5 \delta_{i}+2 \delta_{-i}\right)\left(\phi_{-i} \delta_{i}-2 \phi_{-i} \delta_{-i}\right)\right]\right. \\
& <\frac{7 \delta_{i}}{18}\left[\phi\left(\delta_{-i}-2 \delta_{i}\right)+\phi_{-i}\left(\delta_{i}-2 \delta_{-i}\right)\right]
\end{aligned}
$$

where we used $\delta_{i}>\delta_{-i}$ to derive the second line. Thus, an international permit market can only be mutually beneficial if the condition for global emissions to decrease, equation (A.25), holds.

\section{Details of the numerical illustrations}

For the numerical exercise in Section 6 we parameterize functions (1) using relative energy productivities from the OECD Green Growth Indicators database ${ }^{15}$ for the year 2013. As there is no explicit data on energy productivities for the EU as a whole, we take the productivity of all European OECD countries together as a proxy. According to these numbers, China exhibits approximately one third of the energy productivity of the OECD. In addition, China emits approximately three times as many greenhouse gas emissions as the EU.

${ }^{15}$ DOI:10.1787/9789264202030-en 

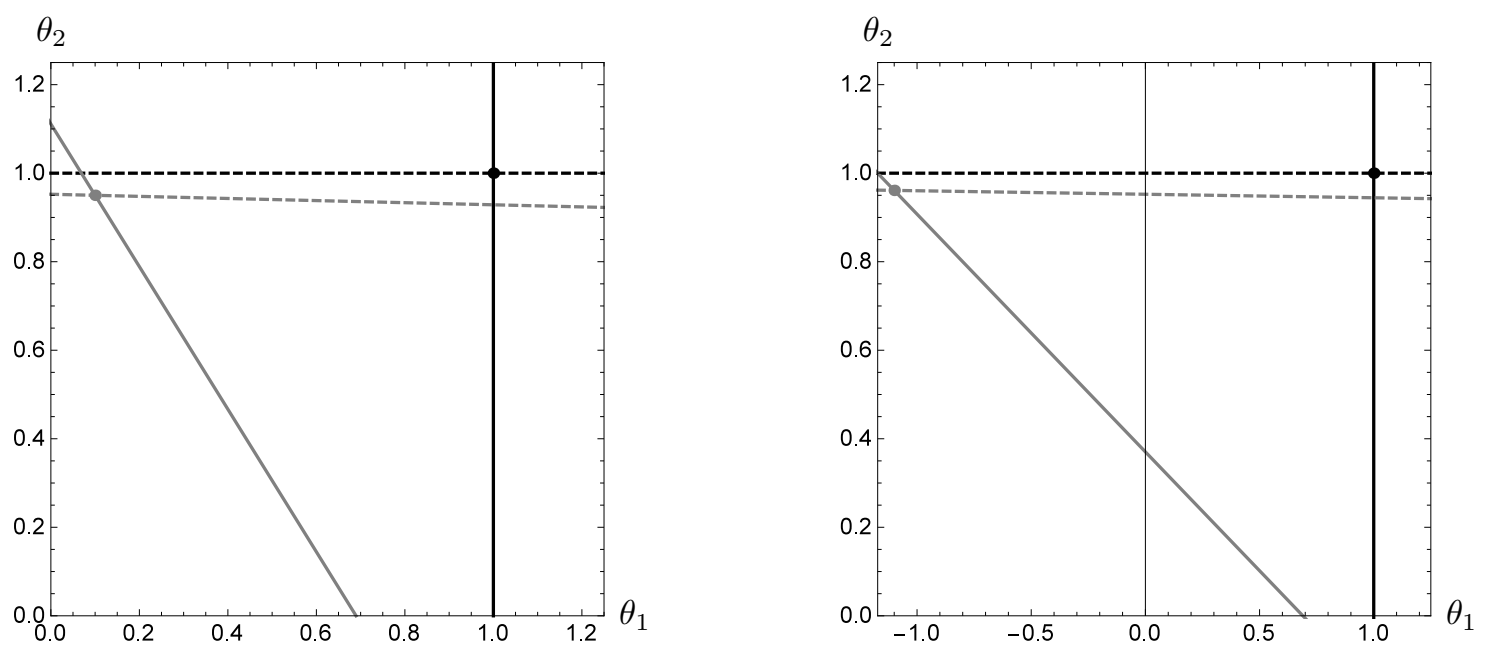

Figure 2: Reaction functions of the principals in country 1 (China, solid) and country 2 (EU, dashed) under the regimes $R=D$ (black) and $R=I$ (gray) at the delegation stage for $\delta_{1}=0.3$ (left) and $\delta_{1}=0.1$ (right).

As a consequence, we obtain for the parameters $\phi_{i}:{ }^{16}$

$$
\frac{B_{1}^{\prime}}{B_{2}^{\prime}}=\frac{\epsilon_{1}}{\epsilon_{2}} \frac{\phi_{2}}{\phi_{1}} \Rightarrow \frac{\phi_{1}}{\phi_{2}}=\frac{\epsilon_{1}}{\epsilon_{2}} \frac{B_{2}^{\prime}}{B_{1}^{\prime}}=3 \cdot 3=9
$$

Following Carlsson et al. (2012) who find that Swedish consumers exhibit roughly four times the WTP for the abatement of greenhouse gas emissions than Chinese consumers, we set the exogenous parameters to:

$$
\epsilon_{1}=3, \quad \epsilon_{2}=1, \quad \phi_{1}=0.9, \quad \phi_{2}=0.1, \quad \delta_{1}=0.15, \quad \delta_{2}=0.6
$$

The results for this benchmark case are shown in Table 1 and Figure 1.

As WTP estimates are plagued by significantly higher systematic estimation errors than carbon efficiency, we run a small sensitivity analysis on the WTP parameters. To this end, we calculate the results for two additional specifications, one in which we increase China's WTP to $\delta_{1}=0.3$, i.e., China exhibits half the WTP of the EU, and one in which we decrease China's WTP to $\delta_{1}=0.1$, i.e., China exhibits only one sixth of the EU's WTP. The results are shown in Table 2 and Figure 2.

For $\delta_{1}=0.3$, we obtain a subgame perfect Nash equilibrium on the delegation stage in which the principal in country 1 delegates to an agent that has a positive WTP for emission reductions. For $\delta_{1}=0.1$, we find that the principal in country 1 delegates in equilibrium

\footnotetext{
${ }^{16}$ We calibrate such that for any positive fraction of business-as-usual emissions country 2 exhibits three times the marginal carbon efficiency of country 1.
} 
Results for $\delta_{1}=0.3$ :

Without strategic delegation

\begin{tabular}{|c|cc|ccccc|cc|}
\hline Regime & $\theta_{1}^{R}$ & $\theta_{2}^{R}$ & $\omega_{1}^{R}$ & $\omega_{2}^{R}$ & $e_{1}^{R}$ & $e_{2}^{R}$ & $E^{R}$ & $V_{1}^{R}$ & $V_{2}^{R}$ \\
\hline$R=D$ & 1 & 1 & 2.73 & 0.94 & & & 3.67 & 3.86 & 2.78 \\
$R=I$ & 1 & 1 & 2.75 & 0.81 & 2.60 & 0.96 & 3.55 & 3.91 & 2.79 \\
\hline
\end{tabular}

With strategic delegation

\begin{tabular}{|c|cc|ccccc|cc|}
\hline Regime & $\theta_{1}^{R}$ & $\theta_{2}^{R}$ & $\omega_{1}^{R}$ & $\omega_{2}^{R}$ & $e_{1}^{R}$ & $e_{2}^{R}$ & $E^{R}$ & $V_{1}^{R}$ & $V_{2}^{R}$ \\
\hline$R=D$ & 1 & 1 & 2.73 & 0.94 & & & 3.67 & 3.86 & 2.78 \\
$R=I$ & 0.1 & 0.95 & 3 & 0.7 & 2.73 & 0.97 & 3.70 & 3.93 & 2.69 \\
\hline
\end{tabular}

Results for $\delta_{1}=0.1$ :

Without strategic delegation

\begin{tabular}{|c|cc|ccccc|cc|}
\hline Regime & $\theta_{1}^{R}$ & $\theta_{2}^{R}$ & $\omega_{1}^{R}$ & $\omega_{2}^{R}$ & $e_{1}^{R}$ & $e_{2}^{R}$ & $E^{R}$ & $V_{1}^{R}$ & $V_{2}^{R}$ \\
\hline$R=D$ & 1 & 1 & 2.91 & 0.94 & & & 3.85 & 4.61 & 2.67 \\
$R=I$ & 1 & 1 & 2.94 & 0.72 & 2.69 & 0.97 & 3.65 & 4.67 & 2.72 \\
\hline
\end{tabular}

With strategic delegation

\begin{tabular}{|c|cc|ccccc|cc|}
\hline Regime & $\theta_{1}^{R}$ & $\theta_{2}^{R}$ & $\omega_{1}^{R}$ & $\omega_{2}^{R}$ & $e_{1}^{R}$ & $e_{2}^{R}$ & $E^{R}$ & $V_{1}^{R}$ & $V_{2}^{R}$ \\
\hline$R=D$ & 1 & 1 & 2.91 & 0.94 & & & 3.85 & 4.61 & 2.67 \\
$R=I$ & -1.10 & 0.96 & 3.13 & 0.63 & 2.79 & 0.98 & 3.77 & 4.68 & 2.66 \\
\hline
\end{tabular}

Table 2: Overview of the outcomes in the subgame perfect Nash equilibria without and with strategic delegation for the sensitivity analysis.

to an agent with an even more negative preference parameter. In both cases, we observe that an international permit market forms without delegation but not in case of strategic delegation. 


\section{References}

Beccherle, J. and J. Tirole (2011). Regional initiatives and the cost of delaying binding climate change agreements. Journal of Public Economics 95, 1339-1348.

Besley, T. and S. Coate (2003). Centralized versus decentralized provision of local public goods: a political economy approach. Journal of Public Economics 87(12), 2611-2637.

Buchholz, W. and C. Haslbeck (1997). Strategic manipulation of property rights in Coasean bargaining. Journal of Institutional and Theoretical Economics 153, 630-640.

Buchholz, W., A. Haupt, and W. Peters (2005). International environmental agreements and strategic voting. Scandinavian Journal of Economics 107, 175-195.

Buchholz, W. and K. A. Konrad (1994). Global environmental problems and the strategic choice of technology. Journal of Economics 60, 299-321.

Burke, M., S. M. Hsiang, and E. Miguel (2015). Global non-linear effect of temperature on economic production. Nature 527, 235-239.

Burtraw, D. (1992). Strategic delegation in bargaining. Economics Letters 38, 181-185.

Burtraw, D. (1993). Bargaining with noisy delegation. The RAND Journal of Economics 24, 40-57.

Carbone, J. C., C. Helm, and T. F. Rutherford (2009). The case for international emission trade in the absence of cooperative climate policy. Journal of Environmental Economics and Management 58, 266-280.

Carlsson, F., M. Kataria, A. Krupnick, E. Lampi, Å. Löfrgen, P. Qin, S. Cung, and T. Sterner (2012). Paying for mitigation: A multiple country study. Land Economics 88, 326-340.

Christiansen, N. (2013). Strategic delegation in a legislative bargaining model with pork and public goods. Journal of Public Economics 97, 217-229.

Copeland, B. R. (1990). Strategic enhancement and destruction of fisheries and the environment in the presence of international externalities. Journal of Environmental Economics and Management 19, 212-226.

Copeland, B. R. and M. S. Taylor (2005). Free trade and global warming: A trade theory view of the Kyoto protocol. Journal of Environmental Economics and Management 49, 205-234.

Crawford, V. P. and H. R. Varian (1979). Distortion of preferences and the Nash theory of bargaining. Economics Letters 3, 203-206.

Dur, R. and H. Roelfsema (2005). Why does centralisation fail to internalise policy externalities? Public Choice 122(3), 395-416.

Fershtman, C. and K. Judd (1987). Equilibrium incentives in oligopoly. American Economic Review 77, 927-40.

Financial Times (2014, September). European energy nominee sells oil holdings to appease MEPs.

Flachsland, C., R. Marschinski, and O. Edenhofer (2009). To link or not to link: Benefits and disadvantages of linking cap-and-trade systems. Climate Policy 9, 358-372.

Golosov, M., J. Hassler, P. Krusell, and A. Tsyvinski (2014). Optimal taxes on fossil fuel in general equilibrium. Econometrica 82, 41-88.

Green, J. F., T. Sterner, and G. Wagner (2014). A balance of bottom-up and top-down in linking climate policies. Nature Climate Change 4, 1064-1067.

Habla, W. and R. Winkler (2013). Political influence on non-cooperative international climate policy. 
Journal of Environmental Economics and Management 66, 219-234.

Habla, W. and R. Winkler (2016, April). Strategic delegation and international permit markets why linking may fail. Discussion Paper Series EfD DP 16-12, Environment for Development.

Harstad, B. (2010). Strategic delegation and voting rules. Journal of Public Economics 94, $102-113$.

Hattori, K. (2010). Strategic voting for noncooperative environmental policies in open economies. Environmental and Resource Economics 46, 459-474.

Helm, C. (2003). International emissions trading with endogenous allowance choices. Journal of Public Economics 87, 2737-2747.

Helm, C. and S. Pichler (2015). Climate policy with technology transfers and permit trading. Environmental and Resource Economics 60, 37-54.

Holtsmark, B. and D. E. Sommervoll (2012). International emissions trading: Good or bad? Economics Letters 117, $362-364$.

Jaffe, J., M. Ranson, and R. N. Stavins (2009). Linking tradable permit systems: A key element of emerging international climate policy architecture. Ecology Law Quarterly 36, 789-808.

Jones, S. R. G. (1989). Have your lawyer call my lawyer: Bilateral delegation in bargaining situations. Journal of Economic Behavior \& Organization 11, 159-174.

Kempf, H. and S. Rossignol (2013). National politics and international agreements. Journal of Public Economics 100, 93-105.

Klepper, G. and S. Peterson (2006). Marginal abatement cost curves in general equilibrium: The influence of world energy prices. Resource and Energy Economics 28, 1-23.

Kopel, M. and M. Pezzino (forthcoming). Strategic delegation in oligopoly. In Handbook of Game Theory and Industrial Organization, Chapter 24.

Loeper, A. (2017). Cross-border externalities and cooperation among representative democracies. European Economic Review 91, 180-208.

Marchiori, C., S. Dietz, and A. Tavoni (2017). Domestic politics and the formation of international environmental agreements. Journal of Environmental Economics and Management 81, 115-131.

Montgomery, W. D. (1972). Markets in licenses and efficient pollution control programs. Journal of Economic Theory 5, 395-418.

Nordhaus, W. D. and J. Boyer (2000). Warming the World: Economic Models of Global Warming Policies. MIT Press.

Perino, G. (2010). How delegation improves commitment. Economics Letters 106, 137-139.

Persson, T. and G. Tabellini (1992). The politics of 1992: Fiscal policy and European integration. The Review of Economic Studies 59, 689-701.

Redoano, M. and K. A. Scharf (2004). The political economy of policy centralization: direct versus representative democracy. Journal of Public Economics 88(3), 799-817.

Roelfsema, H. (2007). Strategic delegation of environmental policy making. Journal of Environmental Economics and Management 53, 270-275.

Segendorff, B. (1998). Delegation and threat in bargaining. Games and Economic Behavior 23, $266-283$.

Siqueira, K. (2003). International externalities, strategic interaction, and domestic politics. Journal of Environmental Economics and Management 45, 674-691. 
Sklivas, S. D. (1987). The strategic choice of managerial incentives. The RAND Journal of Economics 18, 452-458.

Sobel, J. (1981). Distortion of utilities and the bargaining problem. Econometrica 49, 597-619.

Strøm, K. (2000). Delegation and accountability in parliamentary democracies. European Journal of Political Research 37, 261-290.

Vickers, J. (1985). Delegation and the theory of the firm. The Economic Journal 95, 138-147. 